\title{
Long-term changes in invertebrate size structure and composition in a boreal headwater lake with a known minnow introduction
}

\author{
Andrew L. LABAJ,${ }^{1 *}$ Joshua KUREK, ${ }^{1}$ Russ C. WEEBER, ${ }^{2}$ John P. SMOL ${ }^{1}$ \\ ${ }^{1}$ Paleoecological Environmental Assessment and Research Laboratory (PEARL), Department of Biology, Queen's University, \\ Kingston, Canada; ${ }^{2}$ Canadian Wildlife Service (Ontario Region), Environment Canada, Ottawa, Canada. \\ *Corresponding author: a.labaj@queensu.ca
}

\begin{abstract}
To determine the extent and timescale of predation impacts occurring in a historically fishless headwater lake near Sudbury, Canada, we surveyed the larval remains of the invertebrate predator Chaoborus and the pelagic cladoceran Bosmina, within a ${ }^{210} \mathrm{~Pb}$ dated lake sediment core. Size measures of fossil Bosmina mucros, carapaces, and antennules provided inferences of predation intensity. We observed two notable shifts of predation over the span of our $\sim 500$ year record. First, in the late-1800s, a considerable reduction in Bosmina mucro length (an indication of reduced invertebrate predation) occurred following centuries of stable, but high invertebrate predation intensity. Nearly concurrent with reduced invertebrate predation was a substantial decline in sedimentary-inferred Chlorophyll a (a measure of primary production). We hypothesise that turn-of-the century climate warming resulted in a shift in the dominant lake stratification regime at our study site, thus impacting both invertebrate predation intensity and overall primary production. Second, following an observed minnow introduction in the 1980s, the Chaoborus assemblage experienced a minor shift from larger-to smallerbodied species, and total chaoborid concentrations were generally the lowest and most stable of the record. C. americanus was not extirpated from the lake, despite large growth in the minnow population. Although $\mathrm{C}$. americanus is a reliable indicator of fishless conditions when obligate planktivorous fish are considered, our data suggest that absolute fishless conditions may be difficult to establish with confidence using the presence of $\mathrm{C}$. americanus mandibles alone, as this taxon can co-exist with minnow species that are not solely planktivorous. Our palaeolimnological investigation provides temporal insight on predator-prey interactions occurring in small, shallow headwater lakes that have experienced historic shifts in predation due to long-term environmental change as well as a contemporary fish introduction.
\end{abstract}

Key words: Bosmina, Chaoborus, predation, minnow introduction, fishless lakes, paleolimnology.

Received: November 2012. Accepted: January 2013.

\section{INTRODUCTION}

Fishless lakes are hotspots for aquatic biodiversity, showing dominant trophic interactions (such as macro-invertebrates as top predators) that differ largely from lakes with fish present (Wellborn et al., 1996; Schilling et al., 2009). High biodiversity within many small lakes is attributed to the lack of fish predation pressure on invertebrates (Scheffer et al., 2006). Although the distribution of fishless lakes in eastern North America is not well known, illegal and government-sanctioned sport fish stocking in the $20^{\text {th }}$ century likely resulted in the geographic reduction of these distinct aquatic ecosystems (Schilling et al., 2008). Additionally, many fishless lakes from northwestern Ontario, Canada, tend to have high levels of dissolved organic carbon (DOC) (median of $11.5 \mathrm{mg} \mathrm{L}^{-1}$ ) and therefore waters that are highly coloured (Kurek et al., 2010a). High DOC lakes often exhibit increased light attenuation and lower hypolimnetic oxygen levels - abiotic conditions that create challenges for oxygen-sensitive fish species, while providing more optimal habitat for macro-invertebrates that may become the dominant predators (Wissel et al., 2003).
Lakes with fish present are host to a largely different predation regime and food web than those that are fishless. For example, planktivorous fish influence food webs by causing a decrease in the average size of key zooplankton grazers, thus altering nutrient cycling (Brooks and Dodson, 1965; Leavitt et al., 1989). Planktivorous fish selectively prey upon larger zooplankton (Kerfoot, 1975; Wellborn et al., 1996; Wissel et al., 2003), thus large-bodied prey are at a greater risk of predation. Life history traits and behaviour adaptations of zooplankton species can reduce the likelihood of predatory encounter rates (Wellborn et al., 1996), but this is not without some cost to growth and development. For example, diurnal vertical migration (DVM), which reduces encounters with predators such as planktivorous fish and macro-invertebrates, is often at the expense of growth and development as it exposes zooplankton to cooler water temperatures and limited food availability (Lampert, 1989; Loose and Dawidowicz, 1994).

Within fishless lakes, the predation regime is often dominated by macro-invertebrate predators, such as lar- 
vae of the phantom midge Chaoborus (Chaoboridae) and cyclopoid copepods (Kerfoot, 1975; Arnott and Vanni, 1993; Schilling et al., 2009). Chaoborus are gape-limited ambush predators (Spitze, 1985) that are efficient at consuming small zooplankton prey (Mumm, 1997). Chaoborid community composition is a significant determinant of zooplankton community structure, although predation has been found to play less of a role than environmental factors in structuring zooplankton communities in relatively small and shallow Boreal Shield lakes (Kurek et al., 2011). Copepods also exert a strong predation effect upon zooplankton, however their historical abundance is difficult to ascertain, as they leave poorly preserved remains in the sediment record (Frey, 1964).

Historic predation regimes can be reconstructed by examining the fossil remains of organisms within lake sediments (Jeppesen et al., 2001; Palm et al., 2005; Sweetman and Smol, 2006). Fish leave few remains in the sediment record, thus their population dynamics, introduction, or extirpation must often be inferred indirectly from proxy evidence. A major zooplankton predator, $C$. americanus is well-suited as an indirect indicator of fishless conditions (Sweetman and Smol, 2006) due to its lack of DVM in the water column, large size, and pigmentation, which make it susceptible to planktivorous fish predation (Pope et al., 1973; von Ende, 1979; Wissel et al., 2003). Additionally, third and fourth larval instar chaoborids leave well-preserved and readily identifiable remains in the sediment record (Uutala, 1990). As a result, C. americanus has been widely utilised in North America to indirectly track fish introductions and extirpations through time (Lamontagne and Schindler, 1994; Uutala et al., 1994; Schilling et al., 2008). Non-DVM chaoborids in western Europe, such as C. obscuripes, are also used to determine historic fish population dynamics from sediment records (Palm et al., 2005; Luoto and Nevalainen, 2009; Palm et al., 2012). The cladoceran Bosmina, a key herbivore and cosmopolitan zooplankton taxon, also responds to the dominant predation regime within lakes and have been utilised as an indirect indicator of predation (Palm et al., 2005; Alexander and Hotchkiss, 2010; Korosi et al., 2010, 2013). Several Bosmina size attributes, including antennule and mucro length, can vary significantly based upon the dominant predation regime (Kerfoot, 1975). Additionally, Bosmina leaves numerous, well-preserved remains in the sediment record, allowing statistically-valid size measurements to be obtained from sediment intervals (Brahney et al., 2010). Therefore, the examination of both Chaoborus and Bosmina remains from lake sediment records provides an opportunity to assess predation regime shifts across longer periods of time than monitoring data sets or mesocosm studies (when available) allow.

Here, we examine the impacts of a 1980s minnow species introduction and also centennial-scale shifts in predation intensity, within a historically fishless lake near Sudbury, Ontario, Canada. The minnow introduction provided a natural experiment to assess the effects of a relatively recent fish introduction compared to historic shifts in predation intensity. By incorporating the temporal dynamics of a major invertebrate predator (i.e. Chaoborus), as well as its common prey (i.e. Bosmina), we build upon other paleolimnological studies of historic shifts in zooplankton size structure from eastern North America (Leavitt et al., 1989; Korosi et al., 2010, 2012). Whereas most paleolimnological studies recognize the importance of top-down controls of predation on zooplankton (i.e. fish introduction, extirpation, and population shifts), climate-induced shifts in lake thermal structure (Magnuson et al., 1997; Keller, 2007; Quinlan et al., 2012) also have the potential to significantly alter chaoborid-zooplankton dynamics due to temperature-dependent processes (Macphee et al., 2011). This is important to consider, given that, within our study region, $20^{\text {th }}$ century temperature and precipitation patterns are largely different from those of previous centuries (Buhay and Edwards, 1995; Magnuson et al., 1997; Buckley et al., 2004).

\section{METHODS}

\section{Site description and field methods}

The study lake (W16) was selected from among lakes monitored as part of the Environment Canada's Acid Rain Biomonitoring Program (McNicol et al., 1995, 1996). In early-October 2010 , a 35 -cm long sediment core was obtained from W16 (46 $\left.53^{\circ} 3.83^{\prime \prime} \mathrm{N}, 80^{\circ} 49^{\prime} 32.15^{\prime \prime} \mathrm{W}\right)$. W16 is a remote, small (4.4 ha), shallow ( $\sim 8 \mathrm{~m}$ maximum depth) headwater lake $\sim 45 \mathrm{~km}$ northeast of Sudbury, Ontario (Fig. 1). In mid-August of 2005, the lake was thermally stratified (temperatures ranged from $23.4^{\circ} \mathrm{C}$ at 0.5 $\mathrm{m}$ to $8.7^{\circ} \mathrm{C}$ at $7.5 \mathrm{~m}$ ), and anoxic $\left[<1 \mathrm{mg} \mathrm{L}^{-1}\right.$ dissolved oxygen (DO)] below $3 \mathrm{~m}$ water depth. October 2010 water chemistry measurements indicate that W16 is slightly acidic $(\mathrm{pH}=6.6)$, oligotrophic (total phosphorus $=8.4 \mu \mathrm{g} \mathrm{L}^{-1}$ ), and has a relatively stained water colour (DOC $=6.50 \mathrm{mg} \mathrm{L}^{-1}$ ) (Fig. 2). The core was collected from the center of the lake using a gravity corer (Glew, 1989). Sediments were sectioned in the field at intervals of $0.5-\mathrm{cm}$ resolution below $5 \mathrm{~cm}$, and $0.25-\mathrm{cm}$ resolution from $5 \mathrm{~cm}$ to the surface sediments using a vertical extruder (Glew, 1988). Near-annual water chemistry measurements have been obtained at W16 since 1983 (Fig. 2), and fish populations were also monitored once every few years since 1983 (Tab. 1). Minnow trap data indicate that small numbers of minnows may have been present in W16 during the 1980s, but populations dominated by northern redbelly dace (Phoxinus eos) became well established by the mid-1990s (Tab. 1). 




Fig. 1. Maps showing the locations of W16 and the location of the City of Greater Sudbury within the province of Ontario, Canada.
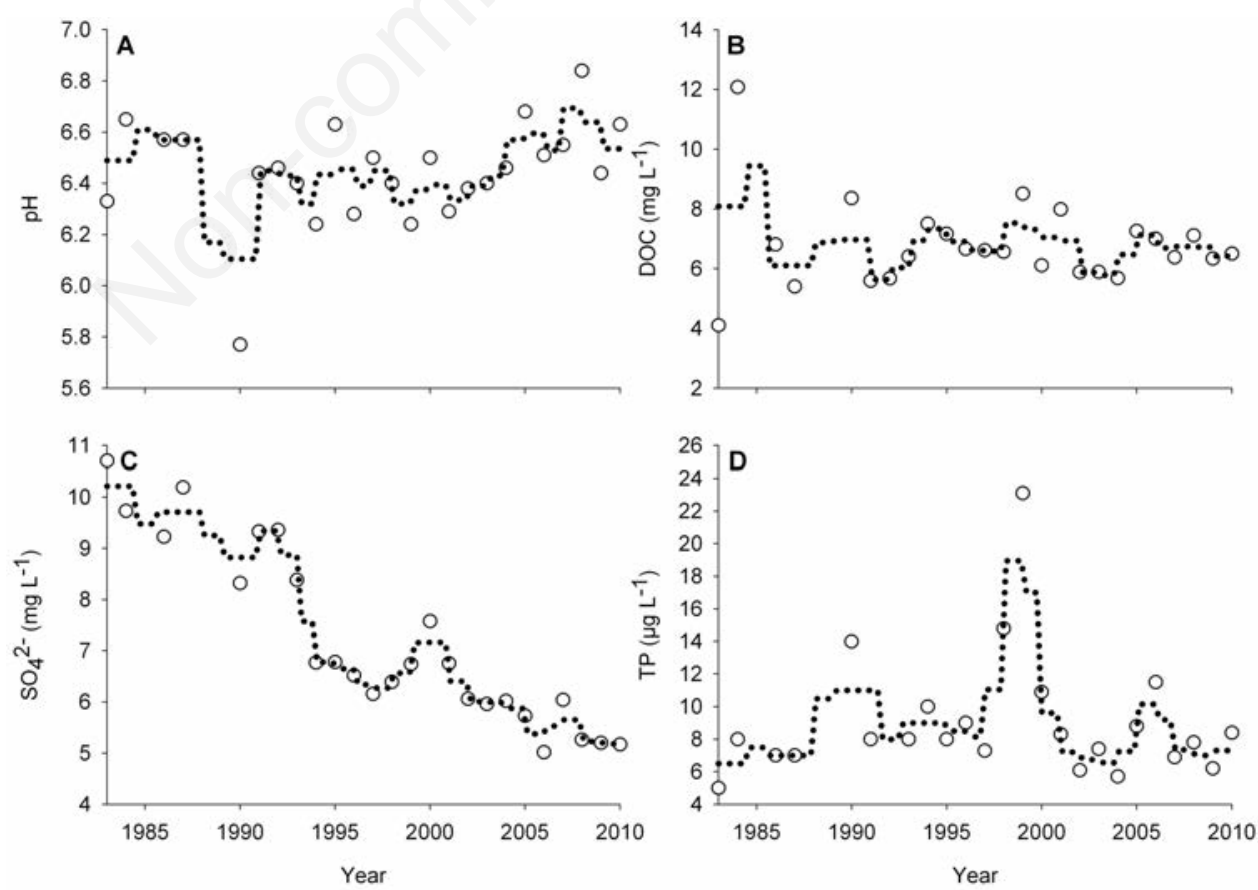

Fig. 2. Selected monitoring data (A, pH; B, DOC; C, $\left.\mathrm{SO}_{4}{ }^{2-} ; \mathrm{D}, \mathrm{TP}\right)$ from W16 between 1983 and 2010. Dotted lines represent running average with sampling proportions of 10\%. Data are from the Canadian Wildlife Service Acid Rain Biomonitoring Program (Ontario region). 


\section{Laboratory methods}

Chaoborus mandibles were isolated from W16 sediments following standard methods outlined in Walker (2001). Wet sediments were preferentially used, with weights ranging from 0.78 to $2.80 \mathrm{~g}$. When wet sediments did not yield sufficient numbers of mandibles, additional freeze-dried sediments were analysed. All sediments were deflocculated with $5 \% \mathrm{KOH}$ solution on a $200^{\circ} \mathrm{C}$ hot plate for $\sim 20$ minutes. Sediments were then poured onto a $100-$ $\mu \mathrm{m}$ mesh sieve and rinsed with deionised water before being transferred into a beaker. Aliquots of each sample were poured into a Bogorov tray and viewed under a dissecting microscope at $\sim 25 \mathrm{X}$ magnification. Each sample was scanned four times to ensure all mandibles were recovered. Forceps were used to remove mandibles and to place them onto a coverslip. Coverslips with mandibles were then permanently mounted onto a slide using Entel$\operatorname{lan}^{\circledR}$ (Electron Microscopy Sciences, Hatfield, PA, USA). A minimum count of 10 mandibles per interval was targeted to ensure an accurate representation of Chaoborus assemblage composition (Quinlan and Smol, 2010). Out of a total of 26 samples, this criterion was achieved 17 times (mandible count summary: $\min =5$, mean $=15.7$, $\max =47$ ).

Bosmina (primarily Bosmina longirostris-type) remains were prepared following methods outlined in Korhola and Rautio (2001). Briefly, wet sediments were weighed and deflocculated with $5 \% \mathrm{KOH}$ solution on a $200^{\circ} \mathrm{C}$ hotplate for $\sim 20$ minutes. Sediments were then poured onto a $38-\mu \mathrm{m}$ mesh sieve, and rinsed with deionised water, then concentrated into a $50-\mathrm{mL}$ vial. Next, three drops of safranin solution and ethanol were added to increase the visibility of remains and as a preservative, respectively. Production of slides involved pipetting $50-\mu \mathrm{L}$ aliquots of the prepared solution onto slides. The number of aliquots used per slide ranged from three to five, depending on the concentration of Bosmina remains. Slides were then mounted using glycerin jelly.
Bosmina size measures were obtained from 26 intervals of the core, generally matching those intervals sampled for Chaoborus.

\section{Measurement and taxonomy}

Chaoborus mandibles were identified using a Leica DMR light microscope under bright-field illumination at 200X magnification. Identifications were based upon a taxonomic key by Uutala (1990). The concentration of chaoborids was calculated by enumerating the number of mandibles found for each species per $1 \mathrm{~g}$ of dry sediment weight. Student's $t$-test was used to compare average chaoborid concentration before and after the mid-1980s minnow introduction.

Measurements of Bosmina antennules, carapaces, and mucros were carried out using a Leica DMR microscope under bright-field illumination at $200 \mathrm{X}$ magnification. Slides were scanned completely in a series of horizontal transects and each non-fragmented Bosmina carapace, mucro, and antennule was measured according to Korosi et al. (2010). Measurements were made using a Retiga digital camera and Northern Eclipse Image Analysis software version 6 (Empix Imaging Inc., Mississauga, Canada). For each interval, at least 40 headshields (with antennules) and 40 carapaces were measured. This is in accordance with Brahney et al. (2010), who demonstrated that a minimum of 35 remains measured was necessary for the detection of meaningful variation in Bosmina size structure.

\section{Dating}

Sediment core samples were analysed for ${ }^{210} \mathrm{~Pb}$ and ${ }^{137} \mathrm{Cs}$ activity using gamma spectrometry techniques to establish a chronology for the past $\sim 150$ years. Preparation of samples for dating followed methods outlined by Schelske et al. (1994). Decays of ${ }^{210} \mathrm{~Pb},{ }^{137} \mathrm{Cs}$, and ${ }^{214} \mathrm{Bi}$ were measured from 15 sediment intervals. Ages based on unsupported ${ }^{210} \mathrm{~Pb}$ concentrations were then calculated

Tab. 1. Numbers of deployed minnow traps and fish collected across years from W16. Data are from the Canadian Wildlife Service Acid Rain Biomonitoring Program (Ontario region).

\begin{tabular}{lccc}
\hline Year & $\begin{array}{c}\text { Number } \\
\text { of traps }\end{array}$ & $\begin{array}{c}\text { Northern redbelly dace } \\
\text { (Phoxinus eos) }\end{array}$ & $\begin{array}{c}\text { White sucker } \\
\text { (Catostomus commersoni) }\end{array}$ \\
\hline 1983 & 6 & 0 & 0 \\
1986 & 6 & 5 & 0 \\
1989 & 6 & 0 & 0 \\
1990 & 6 & 59 & 2 \\
1994 & 6 & 1559 & 0 \\
1999 & 2 & 349 & 0 \\
2001 & 6 & 654 & 0 \\
2004 & 6 & 1591 & 0 \\
2008 & 6 & 1197 & 0 \\
\hline
\end{tabular}


by the constant rate of supply (CRS) model (Appleby, 2001). The ${ }^{137} \mathrm{Cs}$ peak (a proxy for the height of nuclear fallout prior to the 1963 moratorium on nuclear weapons testing) was then compared to ${ }^{210} \mathrm{~Pb}$-inferred ages as an assessment of our radioisotopic dating efforts (Fig. 3).

\section{Visible reflectance spectroscopy Chlorophyll $a$}

To assess temporal patterns in aquatic primary production from W16, sedimentary-inferred Chlorophyll $a$ using visible reflectance spectroscopy (VRS Chl- $a$ ) was measured following Michelutti et al. (2005). This method captures the spectral signatures of sedimentary Chlorophyll $a$ and associated breakdown products between 650 and $700 \mathrm{~nm}$ (Wolfe et al., 2006). In a study designed to test the efficacy of the VRS method, Michelutti et al. (2010) showed that relatively accurate trends across lakes of varying productivity and known eutrophication histories were reconstructed. Sediment intervals from W16 were freeze-dried and sieved through a $125-\mu \mathrm{m}$ mesh sieve, and analysed for VRS Chl- $a$ using a FOSS NIRSystem Model 6500 rapid content analyser. VRS Chl- $a$ concentration was then calculated using a linear regression equation from Michelutti et al. (2005). We emphasise that it is the trends in VRS Chl- $a$ through time, and not the absolute values, that are most informative (Michelutti et al., 2010).

\section{Top-bottom cladoceran assemblage composition}

Cladoceran assemblages were enumerated from the top $(0-0.25 \mathrm{~cm})$ and bottom $(29-29.5 \mathrm{~cm})$ intervals of the W16 core. The top-bottom palaeolimnological approach was chosen as it allows for comparative examination of assemblage changes occurring between modern and preindustrial times in the lake. Specifically, using this snapshot approach we aimed to recognize coarse shifts in the relative abundances of dominant cladoceran groups (i.e. benthic $v s$ pelagic taxa). Cladocera were prepared following standard methods outlined in Korhola and Rautio (2001) and enumerated using standard fossil cladoceran counting guidelines (Kurek et al., 2010b).

\section{RESULTS}

\section{Radiometric dates}

Dates were calculated from the core surface to 19.25



Fig. 3. A, Activity of ${ }^{210} \mathrm{~Pb}$ (black circles) and ${ }^{137} \mathrm{Cs}$ (white circles) $v s$ sediment depth for lake W16. B, Plot of ${ }^{210} \mathrm{~Pb}$ generated age $v s$ sediment depth for lake W16. Error bars represent standard error. Background levels were reached after a depth of $19.25 \mathrm{~cm}$. At depths greater than $19.25 \mathrm{~cm}$, a second-order polynomial regression was used to estimate ages. 
$\mathrm{cm}$, when ${ }^{210} \mathrm{~Pb}$ activity reached background levels (Fig. 3A). Uncertainty within the dates increases with depth from approximately \pm 1 year in surface sediments to \pm 15 years at $19.25 \mathrm{~cm}$. Dates were extrapolated using a second-order polynomial regression (Fig. 3B) for the remainder of the core, with $36.25 \mathrm{~cm}$ (core bottom) roughly corresponding to $\sim$ A.D. 1500 . The ${ }^{210} \mathrm{~Pb}$-inferred date of 1963 corresponded closely with the ${ }^{137} \mathrm{Cs}$ peak at $\sim 13 \mathrm{~cm}$.

\section{Visible reflectance spectroscopy Chlorophyll $a$}

Visible reflectance spectroscopy Chl- $a$ showed stable and high levels from the base of the core to a depth of $\sim 20$ $\mathrm{cm}$ (corresponding to $\sim 1880$ ) (Fig. 4). Visible reflectance spectroscopy Chl- $a$ levels from the basal sediments to $\sim 20$ $\mathrm{cm}$ averaged $0.10 \mathrm{mg} \mathrm{g}^{-1}$ dry weight (dwt) and were on average the highest in the entire record. Then, they declined abruptly until $\sim 17 \mathrm{~cm}(\sim 1920)$, reaching a low of $0.05 \mathrm{mg} \mathrm{g}^{-1} \mathrm{dwt}$. Levels of VRS Chl- $a$ then remained constant at an average of $0.05 \mathrm{mg} \mathrm{g}^{-1} \mathrm{dwt}$ until a depth of $\sim 10$ $\mathrm{cm}$ (corresponding to the approximate time of minnow introduction). After this point, levels showed a steady increase, reaching $0.07 \mathrm{mg} \mathrm{g}^{-1} \mathrm{dwt}$ in the modern intervals of sediment. These were the highest VRS Chl- $a$ values recorded since $\sim 1900$.

\section{Chaoborus assemblages}

Mandible concentrations were substantially more variable below $10.75 \mathrm{~cm}$ (pre- 1980s) than in the modern sediments from $9.75 \mathrm{~cm}$ to present (Fig. 4). A significantly higher average concentration of mandibles occurred in intervals before minnow introduction, compared to those after minnow introduction. $(t=-2.70, \mathrm{P}=0.01, \mathrm{df}=24)$. Additionally, mandible concentration showed greater variability in lower sediment intervals deposited before minnows were introduced to W16 (Fig. 4). Larger-bodied chaoborids dominated the sediment record and on average composed $\sim 90 \%$ of the assemblage (Fig. 4). Concentration of large-bodied chaoborid species decreased and remained at lower levels after the introduction of minnows. Although they appeared several times in the sediment record, smaller-bodied species did not reach the high pre-minnow-introduction concentrations achieved by the larger-bodied species.

\section{Bosmina size structure}

Antennule and carapace lengths remained stable throughout the sediment record, whereas average mucro lengths varied significantly (Fig. 4). Mucro lengths were stable and the highest in the entire record from the bottom of the core to approximately $20 \mathrm{~cm}(\sim 1880)$, averaging 70

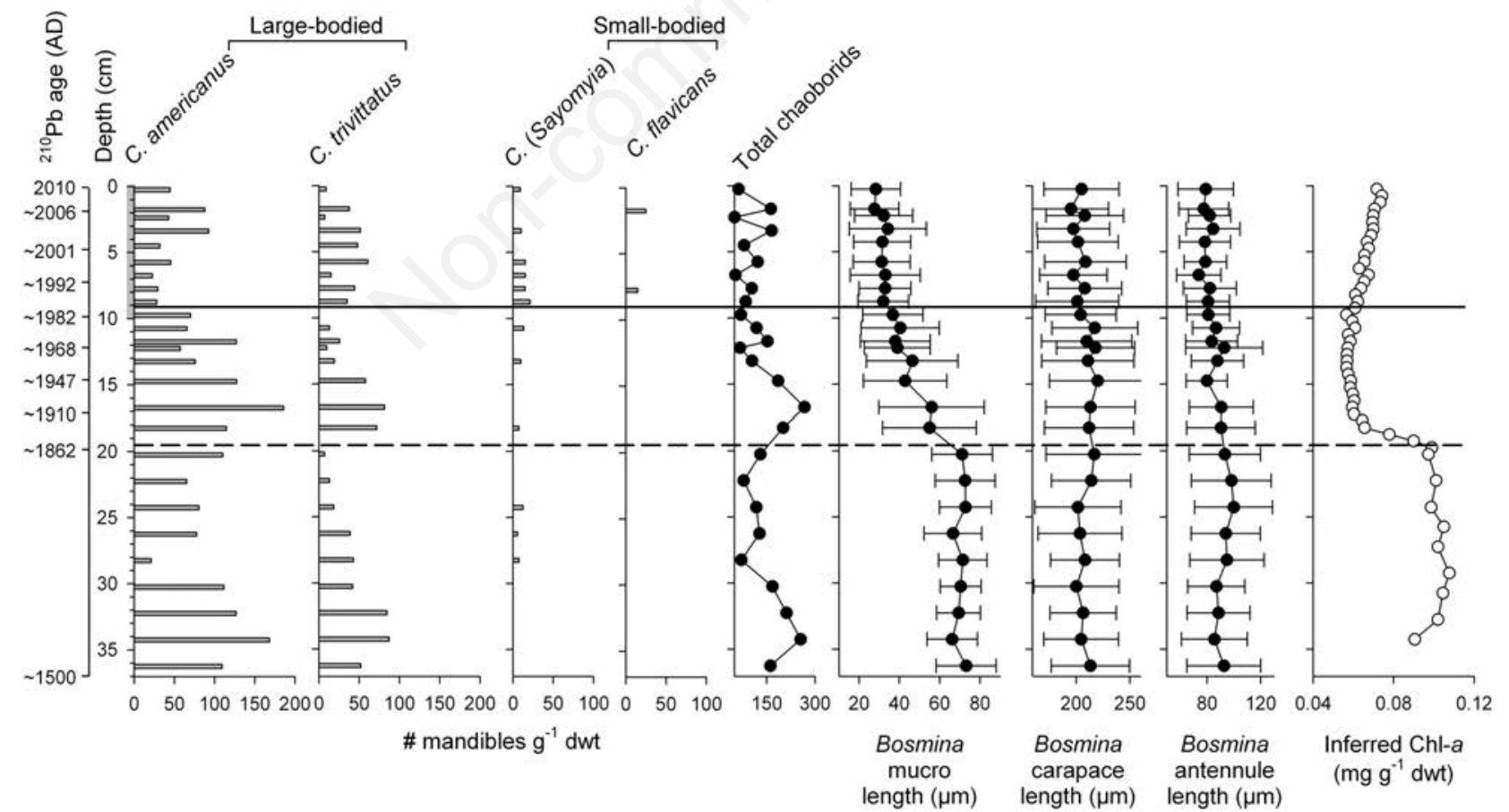

Fig. 4. Stratigraphy of concentrations of individual Chaoborus taxa, total chaoborid concentrations, Bosmina size measures (error bars show one standard deviation), and sedimentary-inferred VRS Chlorophyll $a$. The solid horizontal line marks the $\sim 1980$ s minnow introduction. The dashed horizontal line denotes the late-1800s shift in both VRS Chl- $a$ and mucro length. The shaded y-axis between 10 and $0 \mathrm{~cm}$ represents the period of water chemistry and fish community monitoring at W16. 
$\mu \mathrm{m}$. Mucro lengths declined by $\sim 40 \mu \mathrm{m}$ during the period between $\sim 1880$ and $\sim 1983$. During the period of decline, standard deviation values were comparatively large, indicating a wide range of mucro lengths existed in these intervals. After the minnow introduction, mucro lengths remained stable and values were the lowest in the record, at an average of $31 \mu \mathrm{m}$, for the remainder of the core.

\section{Top-bottom (before and after) palaeolimnological analysis of cladoceran assemblages}

Cladoceran assemblages showed notable changes in the relative abundances of pelagic and littoral taxa (Fig. 5). Through the top-bottom palaeolimnological approach, we observed that pelagic taxa increased relative to littoral taxa. $\mathrm{A} \sim 36 \%$ increase in relative abundance from pre-industrial to modern times was observed in the mainly pelagic taxon Bosmina. Daphnia spp. were never a major contributor to the assemblage and occurred at only $\sim 1 \%$ abundance in both time periods. The dominant littoral taxa in our record, Alona rustica and Chydorus brevilabris, decreased in modern times by $\sim 25$ and $\sim 4 \%$, respectively.

\section{DISCUSSION}

\section{Early ecosystem changes at W16 indicative of a late-1800s shift in stratification regime}

Beginning in the late-1800s, a large-magnitude reduction in predation intensity occurs at W16 as noted by an av- erage Bosmina mucro length decrease of $\sim 40 \mu \mathrm{m}$ (Fig. 4). Shifts in the average length of Bosmina mucros have been interpreted to reflect variation in predation intensity in many palaeolimnological studies (Alexander and Hotchkiss, 2010; Korosi et al., 2013) and modern surveys (Kerfoot, 1975; Black, 1980; Post et al., 1995). Although antennule and carapace lengths may vary with type and intensity of predation, mucro length is often recognised as the most reliable bosminid response to variations in predation (Korosi et al., 2013). Longer mucro length confers an advantage as it makes Bosmina difficult to grasp, handle, and consume by gape-limited invertebrates (Kerfoot, 1975), such as Chaoborus larvae. Therefore, we infer that this late-1800s decrease in mucro length of the dominant zooplankton grazer at W16 is a strong indication that invertebrate predation intensity on Bosmina was greatly reduced. However, we acknowledge that due to poor fossil representation of many invertebrate predators (e.g. copepods, predatory cladocerans, surface-feeding beetles and insects) we are unable to account for the full scope of predation dynamics observed at W16. Additionally, we acknowledge that, due to often fragmented or obscured bosminid remains, genus-level taxonomy was used, and this may have masked size changes arising from a shift in Bosmina species.

Chaoborus assemblages at W16 display several distinct shifts in concentration and species composition before minnow introduction in the 1980s (Fig. 4). The high,



Fig. 5. Relative abundances of cladoceran taxa and groups from top $(0-0.5 \mathrm{~cm})$ and bottom $(29-29.5 \mathrm{~cm})$ sediment intervals of W16. These intervals represent modern (black bars) and pre-industrial (grey bars) time periods at W16. 
but at times variable, concentration of $C$. americanus and C. trivittatus mandibles in sediments deposited prior to $\sim 1980$ is indicative of very low fish planktivory, as these larger-bodied chaoborids are often heavily preyed upon by planktivorous fish (von Ende, 1979; Sweetman and Smol, 2006). In eastern North America, C. americanus has been observed in only a handful of lakes with fish present, and in these instances fish communities showed low richness (Uutala et al., 1994) or C. americanus mandibles were sparse (Schilling et al., 2008). Collectively, our Chaoborus concentration and assemblage composition data suggest that W16 was historically fishless, or at the very least, only low numbers of non-planktivorous fish were ever present.

The close relationship between reduced invertebrate predation intensity and decreased primary production (inferred by VRS Chl- $a$ ) (Fig. 4) suggests that a common change in lake functioning at W16 may structure these measures. One mechanism that explains the apparent correlation between these observed trends is a historic shift in the dominant lake stratification regime at W16. Physical properties of lakes (e.g. stratification regime, water colour and temperature) play important roles in lake plankton dynamics, nutrient cycling, and community structure, which ultimately influence higher trophic levels and lake functioning (Magnuson et al., 1997; Keller, 2007). In many northwestern Ontario lakes, a longer and warmer ice-free season due to recent air temperature increases, in turn, affects fundamental water-column processes of lakes (Magnuson et al., 1997; Schindler et al., 1996; Keller, 2007; Rühland et al., 2010). Quinlan et al. (2012) demonstrate that small lakes with maximum water depths between $\sim 5$ and $8 \mathrm{~m}$ in northwestern Ontario are highly susceptible to climate-induced shifts in thermal regime, although differences in wind exposure, lake morphometry, and water colour among lakes are also important factors to consider. The small size and $\sim 8 \mathrm{~m}$ depth of $\mathrm{W} 16$, in addition to its relatively stained water colour, makes this site especially vulnerable to climate-induced changes in its dominant thermal regime (Magnuson et al., 1997; Keller, 2007; Quinlan et al., 2012).

Climate observations and paleoclimate reconstructions from the Great Lakes region of Ontario show that climate during the $20^{\text {th }}$ century, especially the latter decades, largely differs from conditions over the previous centuries (Magnuson et al., 1997; Buhay and Edwards, 1995; Buckley et al., 2004; Rühland et al., 2010). Specifically, dendroclimatological inferences of climatic conditions during the late1800 s were much cooler and drier than those of the $20^{\text {th }}$ century (Buhay and Edwards, 1995; Buckley et al., 2004). Prolonged periods of less precipitation have been shown to reduce DOC export from the catchment, thus influencing water colour and light transparency (Schindler et al., 1996). Evidence of lower lake levels at W16 is suggested by greater relative abundances of littoral taxa (i.e. A. rustica and C. brevilabris) than pelagic taxa (i.e. Bosmina) during pre-industrial compared to modern times (Fig. 5). If during the mid-to-late-1800s at W16, cooler air temperatures prevailed, lake depth was lower, and DOC concentrations of lake water were reduced, then W16 may have been less likely to record periods of strong thermal stratification. At the turn of the $20^{\text {th }}$ century, as the regional climate became warmer and wetter (Buhay and Edwards, 1995), a shift in the dominant thermal regime at $\mathrm{W} 16$, from a polymictic system that may have only stratified weakly or infrequently, to a lake that experiences longer or more intense periods of thermal stratification, is possible. Therefore, the onset of more regular periods of thermal stratification can explain both the decline in VRS Chl- $a$ levels and the reduction in predation intensity, as well as the close synchronicity between these two events.

Using enclosure experiments in a small, shallow fishless lake from Sudbury, MacPhee et al. (2011) demonstrated that the dominant lake stratification regime and overall water-column temperatures affect Chaoborus predation rates and success. Specifically, it was noted that under isothermal conditions, Chaoborus predation effectively lowered zooplankton abundance; however, under thermally-stratified conditions, Chaoborus did not exhibit a significant predation effect. In thermally stratified lakes, zooplankton that show DVM behaviour are likely to experience at least some periods of cooler water temperatures, compared to zooplankton within nearby isothermal lakes. Cooler water temperatures decrease rates of digestion, metabolism, and respiration (Swift, 1976; Giguère, 1981; Spitze, 1985), all of which often increase prey-handling time, and consequently reduce predation rate and success (MacPhee et al., 2011). Hence, predation intensity as inferred by Bosmina size attributes may be sensitive to climate-induced shifts in lake water properties.

In contrast to the palaeolimnological-based findings of Korosi et al. (2012), which demonstrate that Daphnia may control primary production through grazing, we note a large decline in VRS Chl- $a$ levels, while Daphnia abundances remain exceptionally stable and low (Figs. 4 and 5). Our top-bottom analysis shows no change in Daphnia relative abundance and a large $(\sim 36 \%)$ increase in relative abundance of the smaller-bodied Bosmina between pre-industrial and modern times (Fig. 5). Based on these observed trends, we conclude that grazing by Daphnia were not responsible for the decline in VRS Chl- $a$ levels at W16 beginning in the late-1800s. Again, our data indicate that both primary production and predation intensity were influenced by a shift in the dominant thermal regime of W16. Specifically, after the late-1800s, W16 likely experienced greater frequency, duration, and intensity of thermal stratification due to regional climatic warming (Buhay and Edwards, 1995; Magnuson et al., 1997), com- 
pared to earlier time periods as a primarily polymictic lake. Within polymictic shallow lakes, internal nutrient distribution is often relatively uniform throughout the water column and therefore can support higher levels of primary production (Wetzel, 2001; Søndergaard et al., 2003). However, once a lake thermally stratifies, phosphorus is largely prevented from being entrained from the hypolimnion to the epilimnion for longer periods of time, often resulting in lower levels of overall primary production (Wetzel, 2001). If W16 experienced a historic transition from regular mixing to more frequent or longer periods of thermal stratification, reduced overall primary production in this dystrophic lake is a possible outcome.

\section{Ecosystem changes at W16 after the 1980s minnow introduction}

The average minimum concentration of Chaoborus mandibles is reached during the mid-1980s, corresponding with the timing of minnow introduction at W16. The minnow introduction did not cause the initial decline in Chaoborus concentration at $\sim 1950$, but increased numbers of minnows since the early 1990s (Tab. 1) likely stabilised the chaoborid population at typically the lowest levels observed from the W16 sediment record. Because larger-bodied species such as C. americanus and C. trivittatus can exclude smaller-bodied chaoborids, minnow predation on the more visible, larger-bodied species may have eased predation pressure on smaller chaoborid species; hence, their increased representation at W16 following the minnow introduction (Fig. 4). The lack of complete extirpation of $C$. americanus, despite increasing minnow populations (Tab. 1), is likely due to the diet of the northern redbelly dace, as it feeds on primarily plant material and also invertebrates (Cochran et al., 1988). Similarly, Uutala et al. (1994) observed C. americanus present in both fishless lakes and lakes that supported less than two fish species (albeit at low abundance). Although C. americanus is often extirpated by planktivorous fish species, we note its coexistence with large numbers of northern redbelly dace (Tab. 1).

After minnows became well-established in 1994, Bosmina mucro sizes remain at a constant short length, indicating overall low invertebrate predation intensity. Percent abundance of Bosmina also shows a massive increase of $\sim 36 \%$ from pre-industrial to modern time periods (Fig. 5), suggesting that within-lake conditions have become more favourable for pelagic zooplankton. The introduction of minnows in the 1980s likely resulted in some fish predation upon Chaoborus, thus releasing Bosmina from strong invertebrate predation pressure. Warming annual temperatures in the region (Fig. 6) may also have contributed to an increased rate of growth and reproduction in Bosmina (Vijverberg, 1980). Furthermore, a warmer climate enables phytoplankton to grow faster, and for a longer period of time (Rhee and Gotham, 1981), providing an increased food supply for pelagic zooplankton. This is evidenced by increasing levels of VRS Chl- $a$ since the mid-1980s, which correlate with rising annual temperatures in the Sudbury region (Fig. 6). The large increase in relative abundance of Bosmina was likely caused by a combination of biotic and abiotic factors, which led to its increased success in the lake's more recent history.

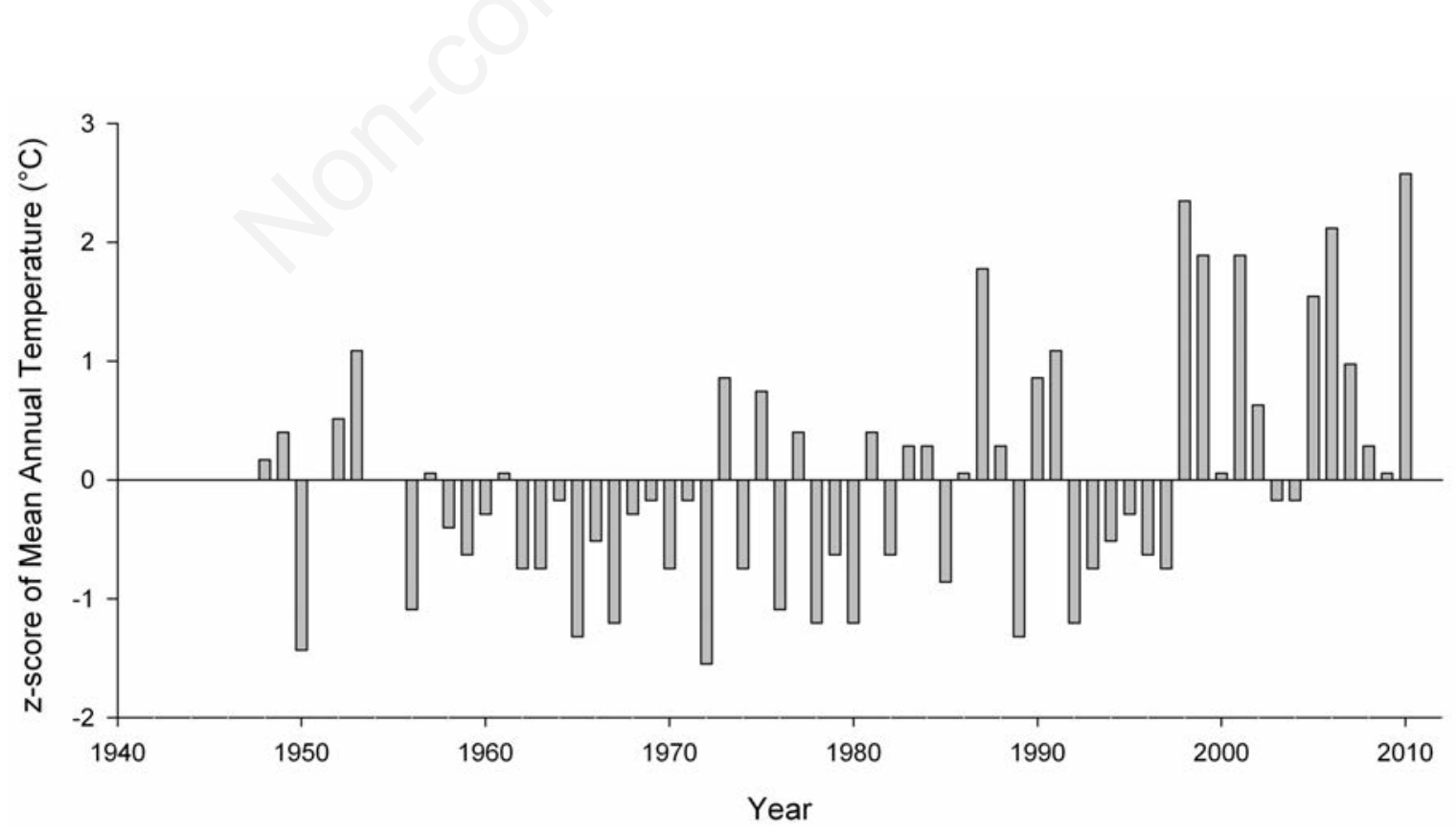

Fig. 6. Standardised values (Z-scores) of annual temperatures for Sudbury, Ontario (climate station 068150). Data obtained from Environment Canada's Adjusted and Homogenized Canadian Climate Records (www.ec.gc.ca/dccha-ahccd/). 
Overall, the scale of predation impacts following the 1980s minnow introduction and their subsequent population increase appears negligible compared to the historic shift in predation intensity that began in the late-1800s.

\section{CONCLUSIONS}

We noted a large-magnitude decrease in invertebrate predation intensity upon a common zooplankton grazer, Bosmina, in the late-1800s at lake W16. Nearly synchronous with the decrease in average Bosmina mucro length, VRS-inferred Chl- $a$ concentrations indicated an abrupt decline in primary production. Collectively, our multiproxy data suggest that W16 experienced a historic shift in its dominant thermal stratification regime, subsequently reducing Chaoborus predation upon Bosmina, and also impacting overall lake primary production. Additionally, we observed that $C$. americanus was not extirpated following the 1980s minnow introduction at W16. Although the presence of $C$. americanus is often interpreted as indicating fishless conditions, its coexistence with a growing population of minnows at W16 provides strong, observational evidence that care should be taken when using indirect measures alone to define fish introduction or extirpation from lake sediment records. Because many small, shallow lakes are fishless and thus support distinct interactions among the biota present, as well as are vulnerable to climate-induced shifts in thermal regime, their value in understanding long-term ecological change continues to be an active research endeavour.

\section{ACKNOWLEDGMENTS}

Support for the Acid Rain Biomonitoring Program was provided by Environment Canada's Acid Rain Program. Funding for sample processing, analysis and manuscript preparation was provided by the Natural Sciences and Engineering Research Council (NSERC) and the Queen's Summer Work Experience Program (SWEP). We thank members of PEARL for constructive comments on early drafts of this manuscript. Two anonymous reviewers also provided direction and critical comments that greatly improved the quality of our manuscript.

\section{REFERENCES}

Alexander ML, Hotchkiss SC, 2010. Bosmina remains in lake sediment as indicators of zooplankton community composition. J. Paleolimnol. 43:51-59.

Appleby PG, 2001. Chronostratigraphic techniques in recent sediments, p. 171-203. In: W.M. Last and J.P. Smol (eds.), Tracking environmental change using lake sediments. 1. Basin analysis, coring, and chronological techniques. Springer, Dordrecht.

Arnott SE, Vanni MJ, 1993. Zooplankton assemblages in fishless bog lakes: influence of biotic and abiotic factors. Ecology 74:2361-2380.
Black RW, 1980. The nature and causes of cyclomorphosis in a species of the Bosmina longirostris complex. Ecology 61:1122-1132.

Brahney J, Routledge R, Bos DG, Pellatt MG, 2010. Changes to the productivity and trophic structure of a sockeye salmon rearing lake in British Columbia. N. Am. J. Fish. Manage. 30:433-444.

Brooks JL, Dodson SI, 1965. Predation, body size, and composition of plankton. Science 150:28-35.

Buckley BM, Wilson RJS, Kelly PE, Larson DW, Cook ER, 2004. Inferred summer precipitation for southern Ontario back to AD 610, as reconstructed from ring widths of Thuja occidentalis. Can. J. Forest Res. 34:2541-2553.

Buhay WM, Edwards TWD, 1995. Climate in southwestern Ontario, Canada, between AD 1610 and 1885 inferred from oxygen and hydrogen isotopic measurements of wood cellulose from trees in different hydrologic settings. Quaternary Res. 44:438-446.

Cochran PA, Lodge DM, Hodgson JR, Knapik PG, 1988. Diets of synoptic finescale dace, Phoxinus neogaeus, and northern redbelly dace, Phoxinus eos: a reflection of trophic morphology. Environ. Biol. Fish. 22:235-240.

Frey DG, 1964. Remains of animals in quaternary lakes and bog sediments and their interpretation. In: Archiv für Hydrobiologie: Ergebnisse der Limnologie. Behiefte 2. Schweizerbart'sche Verlagsbuchhandlung ed., Stuttgart: 114 pp.

Giguère LA, 1981. Food assimilation efficiency as a function of temperature and meal size in larvae of Chaoborus trivittatus (Diptera: Chaoboridae). J. Anim. Ecol. 50:103-109.

Glew JR, 1988. A portable extruding device for close interval sectioning of unconsolidated core samples. J. Paleolimnol. 1:235-239.

Glew JR, 1989. A new trigger mechanism for sediment samplers. J. Paleolimnol. 2:241-243.

Jeppesen E, Leavitt P, De Meester L, Jensen JP, 2001. Functional ecology and paleolimnology: using cladoceran remains to reconstruct anthropogenic impact. Trends Ecol. Evol. 16:191-198.

Keller W, 2007. Implications of climate warming for Boreal Shield lakes: a review and synthesis. Environ. Rev. 15:99112.

Kerfoot WC, 1975. The divergence of adjacent populations. Ecology 56:1298-1313.

Korhola A, Rautio M, 2001. Cladocera and other brachiopod crustaceans, p. 5-41. In: J.P. Smol, H.J.B. Birks and W.M. Last (eds.), Tracking environmental change using lake sediments. 4. Zoological indicators. Springer, Dordrecht.

Korosi JB, Burke SM, Thienpont JR, Smol JP, 2012. Anomalous rise in algal production linked to lakewater calcium decline through food web interactions. P. Roy. Soc. B-Biol. Sci. 279:1210-1217.

Korosi JB, Kurek J, Smol JP, 2013. A review on utilizing Bosmina size structure archived in lake sediments to infer historic shifts in predation regimes. J. Plankton Res.

Korosi JB, Paterson AM, DeSellas AM, Smol JP, 2010. A comparison of pre-industrial and present-day changes in Bosmina and Daphnia size structure from soft-water Ontario lakes. Can. J. Fish. Aquat. Sci. 67:754-762.

Kurek J, Cwynar LC, Weeber RC, Jeffries DS, Smol JP, 2010a. Ecological distributions of Chaoborus species in small, shal- 
low lakes from the Canadian Boreal Shield ecozone. Hydrobiologia 652:207-221.

Kurek J, Korosi JB, Jeziorski A, Smol JP, 2010b. Establishing reliable minimum count sizes for cladoceran subfossils sampled from lake sediments. J. Paleolimnol. 44:603-612.

Kurek J, Weeber RC, Smol JP, 2011. Environment trumps predation and spatial factors in structuring cladoceran communities from Boreal Shield lakes. Can. J. Fish. Aquat. Sci. 68:1408-1419.

Lamontagne S, Schindler DW, 1994. Historical status of fish populations in Canadian Rocky Mountain lakes inferred from subfossil Chaoborus (Diptera: Chaoboridae) mandibles. Can. J. Fish. Aquat. Sci. 51:1376-1383.

Lampert W, 1989. The adaptive significance of diel vertical migration of zooplankton. Funct. Ecol. 3:21-27

Leavitt P, Carpenter S, Kitchell J, 1989. Whole-lake experiments - the annual record of fossil pigments and zooplankton. Limnol. Oceanogr. 34:700-717.

Loose CJ, Dawidowicz P, 1994. Trade-offs in diel vertical migration by zooplankton: the costs of predator avoidance. Ecology 75:2255-2263.

Luoto TP, Nevalainen L, 2009. Larval chaoborid mandibles in surface sediments of small shallow lakes in Finland: implications for paleolimnology. Hydrobiologia 631:185-195.

Macphee SA, Arnott SE, Keller W, 2011. Lake thermal structure influences macroinvertebrate predation on crustacean zooplankton. J. Plankton Res. 33:1586-1595.

Magnuson JJ, Webster KE, Assel RA, Bowser CJ, Dillon PJ, Eaton JG, Evans HE, Fee EJ, Hall RI, Mortsch LR, Schindler DW, Quinn FH, 1997. Potential effects of climate changes on aquatic systems: Laurentian Great Lakes and Precambrian Shield region. Hydrol. Process. 11:825-871.

McNicol DK, Kerekes JJ, Mallory ML, Ross RK, Scheuhammer AM. 1995. The Canadian Wildlife Service LRTAP Biomonitoring Program. 1. A strategy to monitor the biological recovery of aquatic ecosystems in eastern Canada from the effects of acid rain. Canadian Wildlife Service Publ., Gatineau: $28 \mathrm{pp}$.

McNicol DK, Mallory ML, Kerekes JJ. 1996. The Canadian Wildlife Service LRTAP Biomonitoring Program. 3. Site locations, physical, chemical and biological characteristics. Canadian Wildlife Service Publ., Gatineau: 215 pp.

Michelutti N, Blais JM, Cumming BF, Paterson AM, Rühland K, Wolfe AP, Smol JP, 2010. Do spectrally inferred determinations of chlorophyll $a$ reflect trends in lake trophic status? J. Paleolimnol. 43:205-217.

Michelutti N, Wolfe AP, Vinebrooke RD, Rivard B, Briner JP, 2005 . Recent primary production increases in arctic lakes. Geophys. Res. Lett. 32:L19715.

Mumm H, 1997. Effects of competitors and Chaoborus predation on the cladocerans of a eutrophic lake: an enclosure study. Hydrobiologia 360:253-264.

Palm F, El-Daoushy F, Svensson J-E, 2012. Development of subfossil Daphnia and Chaoborus assemblages in relation to progressive acidification and fish community alterations in SW Sweden. Hydrobiologia 684:83-95.

Palm F, Stenson JAE, Lagergren R, 2005. Which paleolimnological zooplankton records can indicate changes in planktivorous fish predation? Verh. Internat. Verein. Limnol. 29:661-666.
Pope GF, Carter JCH, Power G, 1973. The influence of fish on the distribution of Chaoborus spp. (Diptera) and density of larvae in the Matamek River system, Québec. T. Am. Fish Soc. 102:707-714.

Post DM, Frost TM, Kitchell JF, 1995. Morphological responses by Bosmina longirostris and Eubosmina tubicen to changes in copepod predator populations during a whole-lake acidification experiment. J. Plankton Res. 17:1621-1632.

Quinlan R, Paterson MJ, Smol JP, 2012. Climate-mediated changes in small lakes inferred from midge assemblages: the influence of thermal regime and lake depth. J. Paleolimnol. 48:297:310.

Quinlan R, Smol JP, 2010. The extant Chaoborus assemblage can be assessed using subfossil mandibles. Freshwater Biol. 55:2458-2467.

Rhee G, Gotham IJ, 1981. The effect of environmental factors on phytoplankton growth: temperature and the interactions of temperature with nutrient limitation. Limnol. Oceanogr. 26:635-648.

Rühland KM, Paterson AM, Hargan K, Jenkin A, Clark BJ, Smol JP, 2010. Reorganization of algal communities in the Lake of the Woods (Ontario, Canada) in response to turnof-the-century damming and recent warming. Limnol. Oceanogr. 55:2433-2451.

Scheffer M, Van Geest GJ, Zimmer K, Jeppesen E, Søndergaard M, Butler MG, Hanson MA, Declerck S, De Meester L, 2006. Small habitat size and isolation can promote species richness: second-order effects on biodiversity in shallow lakes and ponds. Oikos 112:227-231.

Schelske CL, Peplow A, Brenner M, Spence CN, 1994. Lowbackground gamma counting applications for ${ }^{210} \mathrm{~Pb}$ dating of sediments. J. Paleolimnol. 10:115-128.

Schilling EG, Loftin CS, Degoosh KE, Huryn AD, Webster KE, 2008. Predicting the locations of naturally fishless lakes. Freshwater Biol. 53:1021-1035.

Schilling EG, Loftin CS, Huryn AD, 2009. Effects of introduced fish on macroinvertebrate communities in historically fishless headwater and kettle lakes. Biol. Conserv. 142:30303038 .

Schindler DW, Bayley SE, Parker BR, Beaty KG, Cruikshank DR, Fee EJ, Schindler EU, Stainton MP, 1996. The effects of climatic warming on the properties of boreal lakes and streams at the Experimental Lakes Area, northwestern Ontario. Limnol. Oceanogr. 41:1004-1017.

Søndergaard M, Jensen JP, Jeppesen E, 2003. Role of sediment and internal loading of phosphorus in shallow lakes. Hydrobiologia 506-509:135-145.

Spitze K, 1985. Functional response of an ambush predator: Chaoborus americanus predation on Daphnia pulex. Ecology 66:938-949.

Sweetman JN, Smol JP, 2006. Reconstructing fish populations using Chaoborus (Diptera: Chaoboridae) remains - a review. Quaternary Sci. Rev. 25:2013-2023.

Swift MC, 1976. Energetics of vertical migration in Chaoborus trivittatus larvae. Ecology 57:900-914.

Uutala AJ, 1990. Chaoborus (Diptera: Chaoboridae) mandiblespaleolimnological indicators of the historical status of fish populations in acid-sensitive lakes. J. Paleolimnol. 4:139151.

Uutala AJ, Yan ND, Dixit AS, Dixit SS, Smol JP, 1994. Pale- 
olimnological assessment of damage to fish communities in three acidic Canadian Shield lakes. Fish. Res. 19:157-177.

Vijverberg J, 1980. Effect of temperature in laboratory studies on development and growth of Cladocera and Copepoda from Tjeukemeer, The Netherlands. Freshwater Biol. 10:317-340.

von Ende CN, 1979. Fish predation, interspecific predation, and the distribution of two Chaoborus species. Ecology 60:119128.

Walker IR, 2001. Midges: Chironomidae and related Diptera, p. 43-66. In: J.P. Smol, H.J.B. Birks and W.M. Last (eds.), Tracking environmental change using lake sediments. 4. Zoological indicators. Springer, Dordrecht.
Wellborn GA, Skelly DK, Werner EE, 1996. Mechanisms creating community structure across a freshwater habitat gradient. Annu. Rev. Ecol. Syst. 27:337-363.

Wetzel RG, 2001. Limnology-lake and river ecosystems, $3^{\text {rd }}$ edition. Elsevier Academic Press, Waltham.

Wissel B, Boeing WJ, Ramcharan CW, 2003. Effects of water color on predation regimes and zooplankton assemblages in freshwater lakes. Limnol. Oceanogr. 48:1965-1976.

Wolfe AP, Vinebrooke RD, Michelutti N, Rivard B, Das B, 2006. Experimental calibration of lake-sediment spectral reflectance to chlorophyll $a$ concentrations: methodology and paleolimnological validation. J. Paleolimnol. 36:91-100. 